\title{
De Charlotte Brontë a Jean Rhys: Wide Sargasso Sea como el antidiscurso de Jane Eyre
}

Nair María ANAYA FERREIRA

Universidad Nacional Autónoma de México

"Reader, I married him". Las famosas palabras con las que se inicia el último capítulo de Jane Eyre representan, a los ojos de la heroína del mismo nombre, el triunfo del espíritu ante la adversidad. Pero para la infinidad de críticos que se han acercado a la novela, desde su publicación en 1847 hasta la fecha, la cita da pie a un sinnúmero de interpretaciones que varían según la época y la tendencia crítica desde donde se mire.

Algunos contemporáneos de Charlotte Brontë se mostraron asombrados por la individualidad de este nuevo "escritor", por su capacidad de caracterización, por su pujanza descriptiva y por su habilidad para expresarse en un estilo vigoroso. Otros criticaron airadamente el sentimiento anticristiano de la novela, la vulgaridad de la protagonista y la brutalidad y tosquedad de Rochester. Otros más admiraron la capacidad de observación y de recreación de la realidad cotidiana, que se intensificaba, además, por la profundidad emocional de toda la obra. De entre todos estos puntos de vista surgía también la duda de si el "escritor" era hombre o mujer; confusión iniciada por Brontë misma, al publicar la obra con el título Jane Eyre. An Autobiography. Edited by Currer Bell. Pero a partir de 1850, cuando la identidad de los "Bell" - seudónimo con el que publicaron también las hermanas de Charlotte, Emily y Anne- se dio a conocer, la reputación de Charlotte quedó bien establecida.

En el otro extremo encontramos las interpretaciones modernas y predominantemente feministas que van desde el ensayo que Virginia Woolf escribió en 1916 para celebrar el centenario del nacimiento de Brontë, hasta el famoso análisis de Sandra Gilbert y Susan Gubar en ese otro famoso texto canónico del feminismo, The Madwoman in the Attic (1979), en el que los personajes femeninos inestables (por no llamarlos locos o dementes) de la novela victoriana escrita por mujeres se estudian como dobles o contrapartes -el área oculta o suprimida de la sexualidad- de las protagonistas. 
Dentro de todo este proceso de canonización, que se acerca ya a los ciento cincuenta años, Jane Eyre se ha constituido en uno de esos fenómenos literario-culturales de los que no muchas obras llegan a formar parte, pues no sólo es sujeto de estudio crítico-académico, sino que también goza de enorme popularidad entre el público del mundo entero que aprecia la novela ya sea en su manifestación textual o en sus diversas adaptaciones para el cine, el teatro, la radio y la televisión (sin olvidar que es un texto obligatorio del programa de estudio inglés).

Sin embargo, dentro de este proceso infinito de interpretación de un texto -proceso por medio del cual se intenta buscar la apertura de éste con el objeto de lograr que se establezca un diálogo sobre el texto como parte de la vida creativa de la comunidad en el presente y en el futuro ${ }^{1}$ poco se ha escrito sobre una novela publicada en 1966 y que constituye, en mi opinión, un interesante ejemplo de cómo una clara situación intertextual en una obra literária no sólo pude abrir una nueva dimensión crítica de análisis e interpretación, sino que, de hecho, puede resaltar y revertir simultáneamente los valores intrínsecos de la obra fuente y, más aún, llenar los silencios de esta última de tal forma que nos permite una reconstrucción total de la misma.

Me refiero a Wide Sargasso Sea de la escritora nacida en la isla de Dominica, Jean Rhys. Wide Sargasso Sea (publicada en 1966) es la narración de la infancia y juventud de Bertha Mason, la esposa demente de Rochester, la loca del ático, en el Caribe. De manera magistral, Jean Rhys da vida a este ser misterioso - que en la novela de Brontë se ha venido considerando como un mero avatar de Jane Eyre, como su "doble oscuro", según la interpretación de Gilbert y Gubar- y conforme 10 humaniza saca a la superficie una serie de preconcepciones que están implícitas en Jane Eyre y que de hecho son las que sostienen cultural e ideológicamente a esta obra.

Así, se da un juego intertextual por demás desafiante y provocador. Por un lado, podemos leer la novela de Rhys como un texto único e individual, con fuerza propia e independiente, cuya trama capta la atención del lector y lo hace reflexionar no sólo sobre la situación de la mujer durante el siglo XIX, sino también sobre las relaciones de desigualdad que se dan en todo fenómeno de colonización. Por otro lado, al mismo tiempo, Wide Sargasso Sea actúa como contrapunto textual, cultural e ideológico de Jane Eyre y logra tan bien su cometido que el

\footnotetext{
1 Véase Mario VALDÉs, World-Making. The Literary Truth-Claim and the Interpretation of Texts. Toronto, Universidad de Toronto, 1992, p. 12.
} 
lector se ve obligado, como ya dije antes, a reescribir paso a paso la novela inglesa.

La protagonista caribeña de Wide Sargasso Sea, la heredera criolla Antoinette Cosway, es la antítesis de la institutriz inglesa Jane Eyre. Carece, para empezar, de esa fuerza interna que guía a Jane Eyre durante su larga búsqueda espiritual. A pesar de ser muy bella y de pertenecer a la clase dominante - si bien ya desposeida - de Jamaica, Antoinette no sabe ganarse el respeto de los que la rodean y su vida sigue un proceso gradual de degradación que la lleva finalmente a la locura y la muerte. Jane Eyre, lo sabemos, se sobrepone a todos y cada uno de los obstáculos a los que se enfrenta y, en un espíritu puritano, casi a la manera de Moll Flanders e incluso de Pilgrim's Progress, se ve premiada con el trofeo anhelado: su matrimonio con Rochester (además de una herencia millonaria que proviene del Caribe).

La estructura narrativa de Wide Sargasso Sea se basa en una serie de paralelismos que se contraponen a la estructura de Jane Eyre: la vida de Jane gira en torno al trabajo, mientras que Antoinette es indolente. Jane es huérfana, pero a pesar de estar siempre sola es capaz de tomar decisiones; Antoinette tiene familia pero es una niña desatendida y rechazada, que se encierra cada vez más en sí misma. La estancia de Jane en el internado del estricto y puritano señor Brocklehurst le da las armas espirituales para enfrentarse a las tentaciones del mundo exterior; para Antoinette, su estadía en el convento católico incrementa su añoranza por la muerte y le consume la vitalidad. Ambas tienen "hermanos" tiránicos, pero mientras Jane resiste los embates de John Reed y St. John Rivers, Antoinette es victimada y traicionada por Daniel Cosway y Richard Mason. Finalmente, el elemento que las une, su relación con Rochester: mientras que Jane lo escoge y lucha por él, a Antoinette se le impone el matrimonio con él y este solo episodio marca el cruce de caminos donde las dos vidas encuentran -y a la vez siguen-direcciones opuestas (con la ayuda, por supuesto, de esas coincidencias que pertenecen más bien a los cuentos de hadas, como la herencia milagrosa que cambia el curso de la vida de Jane, a diferencia de la realidad histórica que priva a Antoinette de la suya: su familia había perdido todo a raiz de.' proceso de emancipación de los esclavos en Jamaica, y la poca herencia que le queda pasa a pertenecer a Rochester).

Pero más allá de estos paralelismos evidentes, Wide Sargasso Sea carcome las raíces que sostienen a Jane Eyre a partir de su estrategia textual. A pesar de que la novela de Charlotte Brontë trata sobre un personaje marginado dentro de la corriente central de la sociedad inglesa 
de mediados del siglo XIX, su textura narrativa es sorprendentemente firme y directa. De hecho, fue precisamente la fuerza tan directa de la voz narrativa en primera persona uno de los factores que sorprendieron y disgustaron a muchos de los críticos contemporáneos de Brontë, y es lo que, como sugiere Raymond Williams, nos permite traspasar la mera imagen negativa y estereotipada de la institutriz como ser represivo, poco femenino y sin atractivo físico para llegar a esta poderosa voz narrativa que tiene la capacidad de establecer una relación íntima con el lector.

De hecho, tanto Charlotte Brontë con Jane Eyre, como Emily con Wuthering Heights forman parte de esa nueva generación de escritores (en la que se puede incluir a Dickens, Thackeray y a la señora Gaskell) quienes, durante los años de 1847 y 1848, articulan la crisis de conciencia que sacudió a la sociedad inglesa durante esa década. Una crisis de conciencia que comenzó a cuestionar las primeras consecuencias de la gran Revolución industrial, que había transformado a Inglaterra en una sociedad eminentemente urbana e industrializada y que se manifiesta, en el caso de las hermanas Brontë, en el predominio de la pasión y la intensidad de sentimientos. ${ }^{2}$

De esta forma, la fuerza de la narración en primera persona de Jane Eyre rompe de entrada con la estructura de sentimiento que dominaba la época y que ponía énfasis en un modo social que se puede considerar como "masculino" y que se basaba sobre todo en el control de uno mismo y en la austeridad. (Las tensiones que esto producía aparecen, en primera instancia, en la necesidad de usar seudónimos masculinos, como los adoptados por las mismas hermanas Brontë o por George Eliot.)

Sin embargo, esta ruptura es, hasta cierto punto, superficial, pues si bien es cierto que la institutriz creada por Charlotte Brontë trasciende las limitaciones impuestas a su posición social, también es verdad que sólo lo logra apoyándose en esas mismas nociones sociales y culturales que se propone rebasar. Seré más explícita. La figura de la institutriz en la Inglaterra victoriana ha sido tema de análisis sociológico y literario, y ha venido a representar la vulnerabilidad de la mujer en un medio en el que se le negaba, prácticamente, toda posibilidad de participación económica. En la sociedad patriarcal inglesa, la mujer tenía pocas alternativas: si era adinerada, el matrimonio era no sólo un anhelo sino un refugio que perpetuaba la seguridad de la casa paterna (y de paso

2 Véase Raymond WiLLiaMs, The English Novel, from Dickens to Lawrence. Londres, The Hogarth Press, 1984, introd. y cap. 2. 
garantizaba la seguridad económica del marido, que adquiría automáticamente los bienes de su cónyuge). Pero si la mujer aspiraba a tener educación e independencia y carecía de un ingreso privado terminaba, por lo general, como institutriz, una profesión por demás ambigua pues, sin ser propiamente un elemento de la servidumbre, se le trataba como tal, aunque se le exigía buena presentación, buenos modales, paciencia y conocimientos.

Las tensiones implícitas en esta situación forman la columna vertebral de Jane Eyre. Trabajar como institutriz es la única opción abierta para una huérfana que ha sido expulsada de la casa adoptiva de sus tíos, pero que ha tenido una educación social e intelectual. A pesar de carecer de recursos y de no ser atractiva, se le reconoce como un ser "superior", tanto por los sirvientes como por los aristócratas, que perciben en su comportamiento algo que ellos toman por altanería y que los hace sentir definitivamente incómodos.

Jane misma está consciente de sus diferencias y, a pesar de su aparente debilidad física (que ella menciona desde el segundo párrafo de la novela), demuestra una gran fortaleza espiritual que la sostiene a lo largo de la trama. Ahora bien, si nos preguntamos en qué consiste dicha fortaleza espiritual veremos que ésta se ve definida por un sentido innato de lo que se ha dado por llamar "Englishness", la esencia de lo inglés o 'anglicidad', y que consiste, en este caso en particular, en una conciencia de clase, en la necesidad de tener educación, en un sentido religioso de la vida, en el predominio de las instituciones sociales y en la importancia del trabajo y la creatividad. Y es aquí donde vemos que Jane Eyre es una novela que se apropia de ciertos principios fundamentales para la mitificación de lo que constituye la "cultura inglesa" (io será tal vez la "imagen" de esa cultura inglesa?).

Uno de los primeros elementos definitorios de dicha imagen es una sorprendente conciencia de clase, sorprendente por la forma en que aparece manifestada en la narración. Cuando la pequeña Jane sufre un colapso nervioso después de que la tía, la señora Reed, la encierra en el cuarto oscuro donde murió su esposo, siente una inmensa necesidad de escapar del ambiente claustrofóbico de Gateshead. Sin embargo, cuando el médico le pregunta si le gustaría vivir con algún otro pariente aunque fuera pobre, la niña evalúa la situación (ya mediatizada, por supuesto, por la Jane adulta):

I reflected. Poverty looks grim to grown people; still more so to children: they have not much idea of industrious, working, respectable 
poverty; they think of the word only as connected with ragged clothes, scanty food, fireless grates, rude manners, and debasing vices: poverty for me was synonymous with degradation. ${ }^{3}$

\section{Y después responde:}

"No; I should not like to belong to poor people" [...]

"Not even if they were kind to you?"

I shook my head; I could not see how poor people had the means of being kind, and then to learn to speak like them, to adopt their manners, to be uneducated, to grow up like one of the poor women I saw sometimes nursing their children or washing their clothes at the cottage doors of the village of Gateshead: no, I was not heroic enough to purchase liberty at the price of caste (pp. 56-57, el subrayado es mío). ${ }^{4}$

Muy sutilmente, esta conciencia de clase subyace la trama de la novela y sale a la superficie en los momentos en que es necesario definir socialmente a la protagonista. Así como la niña Jane se sitúa en la pobreza y la rechaza, la joven institutriz no acepta tampoco los intereses, los contactos y las conveniencias de los aristócratas, si bien no se atreve a juzgar los principios y el comportamiento del señor Rochester y la señorita Ingram, pues reconoce que actúan de acuerdo con ideas y principios inculcados desde la niñez (p. 216). ${ }^{5}$

${ }^{3}$ Charlotte BrontE, Jane Eyre. Harmondswroth, Penguin, 1975, p. 56. De aquí en adelante, todas las referencias a la novela corresponderán a esta edición, y se indicará entre paréntesis el número de página. "Reflexioné. La pobreza les parece penosa a las personas mayores, y más aún a los niños, que no tienen la menor idea de una pobreza industriosa, trabajadora y respetable. Piensan que la palabra pobreza significa ropas harapientas, alimentación escasa, estufa sin fuego, modales rudos y vicios degradantes. Para mí la pobreza era sinónimo de degradación". (La versión en español corresponde a Rafael Jiménez Orderiz [México, Porrúa, 1983, p. 18].)

4 "-No me gustaría pertenecer a la clase pobre - fue mi respuesta.

"- ¿Ni siquiera aun siendo bondadosos con usted?

"Movi la cabeza en señal de duda; no podia comprender en qué forma podrian los pobres arreglarse para ser buenos, y además tendría que hablar como ellos, adoptar sus maneras, ser mal educada, crecer como una de las pobres mujeres que veía a veces cuidando a sus hijos o lavando sus ropas a la puerta de las casas de la aldea de Gateshead; no, no era tan heroica como para comprar mi libertad a costa de mi categoría". (Idem.) La última palabra, "categoría", pierde la carga significativa del inglés "caste" ("casta"), con enormes implicaciones en una sociedad tan jerárquica como la inglesa.

${ }^{5}$ Ibid., p. 136. 
Se da entonces una de las tantas paradojas que componen la novela. Jane Eyre, en su incesante observación y cuestionamiento de la sociedad que la rodea, se siente un tanto inmune a los prejuicios que dominan a los demás, pues, según ella:

Prejudices [...] are most difficult to eradicate from the heart whose soil has ever never been loosened or fertilized by education; they grow there, firm as weeds among stones (p. 367). ${ }^{6}$

Sin embargo, su educación moral y sentimental se lleva a cabo, en gran medida, dentro de los parámetros impuestos por ciertas ideas preconcebidas.

Su largo proceso de aprendizaje -cuyo obstáculo mayor es, por supuesto, su negativa a casarse con Rochester- culmina no en un ambiente urbano $o$ en las delicias de una situación acomodada, sino en una pequeña comunidad situada en una región inhóspita al norte de Inglaterra, donde Jane puede ser verdaderamente ella misma: una mujer independiente, con cierto grado de poder, activa y capaz de percibir y capturar al mundo de una forma positiva y constructiva.

Irónicamente, después del lujo y el ocio de Thornfield Hall, su estancia en un ambiente austero (que equivaldría a esa pobreza que ella rechazó de niña) le permite no sólo redefinirse y aceptarse sino también ejercer lo que será el segundo elemento constitutivo de su fortaleza espiritual: la educación. Sin embargo, y aquí es donde reside la ironía, la redefinición de Jane se logra entre las niñas analfabetas de.Morton, a las que se refiere siempre en términos de rústicas, no refinadas, incultas, etcétera. Es decir, Jane se convierte en un modelo arquetípico de la mujer inglesa educada cuya misión es "civilizar" a los menos afortunados (lo que precisamente constituye, para algunos críticos, el elemento central del imperialismo).

Así, luego del primer encuentro con las que serán sus alumnas y de sentirse degradada por creer que ha descendido en la "escala social", Jane evoluciona espiritualmente después de cumplir su papel de educadora. Su función es clara. A pesar de que la mayoría de las niñas son "unmannered, rough, intractable, as well as ignorant", 7 Jane no debe olvidar que "these coarsely-clad little peasants are of flesh and blood as

6 “4...] los prejuicios son muy dificiles de borrar del corazón, cuyo suelo nunca ha sido ablandado o fertilizado por la educación; crecen allí firmes como la maleza entre las piedras". (Ibid., p. 247.)

7 “Algunas son groseras, rudas, intratables, además de ignorantes". (Ibid., p. 260.) 
good as the scions of gentlest genealogy; and that the germs of native excellence, refinement, intelligence, kind feeling, are as likely to exist in their hearts as those of the best-born". ${ }^{8}$ Por lo tanto, Jane tendrá inevitablemente que cultivar esa semilla: "My duty will be to develop these germs: surely I shall find some happiness in discharging that office. Much enjoyment I do not expect in the life opening before me: yet it will, doubtless, if I regulate my mind, and exert my powers as I ought, yield me enough to live on from day to day" (p. 385). ${ }^{9}$

De institutriz de una niña privilegiada pasa a ser maestra de niñas marginadas: su vida adquiere una nueva dimensión que modifica la imagen que Jane tenía de los campesinos ingleses, en un interesante proceso de representación cultural y reafirmación nacionalista:

[...] I stood with the key in my hand, exchanging a few words of special farewell with some half-dozen of my best scholars: a decent, respectable, modest, and well-informed young women as could be found in the ranks of the British peasantry. And that is saying a great deal; for, after all, the British peasantry are the best taught, best mannered, most self-respecting of any in Europe: since those days I have seen paysannes and Bäuerinnen; and the best of them seemed to me ignorant, coarse, and besotted, compared with my Morton girls ( $p$. 415). ${ }^{10}$

La conciencia de clase se transforma en una conciencia nacionalista que trasciende las limitaciones de grupos-castas individuales y que, dentro de la narrativa, conduce a un encomio patriotero que absorbe, por así decirlo, la textura individual-feminista de la novela.

8 “[...] estas pequeñas campesinas de grosera apariencia tienen sangre y carne tan buenas como la de los retoños de superior genealogía; y que los gérmenes de natural bondad, refinamiento, inteligencia y sentimiento pueden hallarse tanto en sus pechos como en los de los mejor nacidos". (Idem.)

9 "Mi deber consistirá en hacer desarrollar esos gérmenes, y sin duda encontraré algo de felicidad en el cumplimiento de este deber. No espero muchas alegrías de la vida que se abre ante mi; sin embargo, estoy segura de que la misma me rendirá algunas para ir pasando los días, si regulo mi espíritu y encamino mis esfuerzos hacia donde es debido". (Idem.)

10 "[...] permanecía con [la llave] en la mano intercambiando unas palabras de despedida con algunas de sus mejores alumnas: jóvenes tan decentes, respetables, modestas y bien instruidas como las mejores que podrían encontrarse en las filas de los campesinos británicos. Y es mucho decir porque, después de todo, los campesinos británicos son los más instruidos, los mejores modales y más respetuosos de toda Europa. Después de aquellos días he visto paysannes y bäuerinnen; y las mejores de ellas me parecieron ignorantes, burdas y tontas, comparadas con mis niñas de Morton". (Ibid., p. 282.) 
El registro del último capítulo de Jane Eyre es significativo en tanto que suprime la fuerza narrativa de la primera persona que ha caracterizado todo el texto. La focalización narrativa implícita en la primera oración de dicho capítulo - "Reader, I married him"- pasa de la exultación del logro individual a lo que sería una narración en tercera persona: el lector, al que Jane Eyre se ha dirigido a lo largo de la novela, se entera de cuál ha sido el fin de los otros personajes. Por un lado, tenemos que las hermanas Rivers, Diana y Mary, viven felizmente casadas con un capitán de la marina y un pastor anglicano: dos de las profesiones "dignas" y socialmente aceptadas durante la Inglaterra del siglo XIX. Por otro lado, vemos la importancia primordial de dos elementos constitutivos de la anglicidad, representados por Adèle y St. John Rivers: la educación y la religión, conceptos que, como ya dije antes, sostienen la estructura de Jane Eyre, pero que en este último capítulo transmutan 'la interiorización narrativa en un consentimiento jingoista del imperialismo por parte de la protagonista.

La educación y la religión son los ejes sobre los que gira el desarrollo de Jane Eyre, no sólo como personaje sino como símbolo, en última instancia, del imperialismo inglés. Para Jane,.la educación, en su sentido más amplio, es capaz de transformar no sólo el comportamiento y la mentalidad de un individuo, sino que de hecho es el medio por el que se pueden erradicar sus características genético-culturales; es decir, la educación es el instrumento central en un proceso de amoldamiento cultural tendiente a lograr ese factor tan importante en la sociedad inglesa: el consenso.

En el nivel individual, la francesita Adèle constituye el mejor ejemplo de dicho proceso: una vez que se le institucionaliza (entra a un internado, digamos, "progresista"), llega a personificar un modelo adecuado de anglicidad eclipsando así sus antecedentes franceses:

As she grew up, a sound English eduaction corrected in a great measure her French defects; and when she left school, I found in her a pleasing and obliging companion -docile, good-tempered, and well-principled (p. 475). ${ }^{11}$

En el nivel social, la labor evangelizadora de St. John Rivers articula la unión intrínseca entre educación y religión como parte de un proceso

'11 “Al crecer, una sólida educación inglesa corrigió en gran parte sus defectos franceses; y tuve en ella una compañera agradable y simpática, dócil, de buen carácter y buenos principios". (Ibid., p. 325.) 
civilizador mucho más extenso. El hecho de que los últimos párrafos de la novela se dediquen por completo a la vida como misionero de St. John Rivers ha sido cuestionado por varios críticos, pero confirma en gran medida lo que he venido argumentando hasta aquí. Al ceder el escenario a su primo, Jane da por sentado y acepta sin cuestionarse el lenguaje mitificador del proceso imperialista. St. John Rivers culmina, en una dimensión global, la lucha individual de Jane a lo largo de la novela, no sólo como parte de su propia evolución psicológica y moral, sino también como parte de su función educativo-doctrinaria con las niñas de Morton y con Adèle.

Así, St. John Rivers "sacrifica" su vida por la difusión de los valores del imperialismo, disfrazados de dogmas religiosos y de nociones relacionadas con la evolución y superación moral de los pueblos menos afortunados (en este caso, la India):

A more resolute, indefatigable pioneer never wrought amidst rocks and dangers. Firm, faithful, and devoted, full of energy and zeal, and truth, he labours for his race; he clears their painful way to improvement; he hews down like a giant the prejudices of creed and caste that encumber it. He may be stern; he may be exacting; he may be ambitious yet; but it is the sternness of the warrior Greatheart, who guards his pilgrim convoy from the onslaught of Apollyon. His is the exaction of the apostle, who speaks but for Christ [...] His is the ambition of the high master-spirirt, which aims to fill a place in the first rank of those who are redeemed from the earth - who stand without fault before the throne of God, who share the last mighty victories of the Lamb, who are called, and chosen, and faithful (p. 477). ${ }^{12}$

El nivel de abstracción de este lenguaje alegórico que tanto recuerda al Pilgrim's Progress de Bunyan, y que nos llega por la narradora en

\footnotetext{
12 'Nunca luchó entre rocas y peligros un pionero más resuelto e infatigable. Firme, fiel y devoto, pletórico de energías, de celo y verdad, trabaja por su raza; le allana el doloroso camino hacia el mejoramiento, destruye como un gigante los prejuicios de credo y de casta que la agobian. Quizá sea exigente o duro; puede que sea hasta ambicioso; mas la suya es la dureza del guernero Greatheart, que defiende a su convoy de peregrinos del ataque de Apollion. La suya es la dureza del apóstol que sólo habla para Cristo cuando dice: 'Quienquiera que venga después de Mí, que renuncie a sí mismo, tome la cruz y me siga'. La suya es la ambición del espíritu elevado, que aspira a llenar un lugar en la primera fila de quienes han redimido comarcas enteras, que permanecen libres de culpa delante del trono de Dios, que contribuyen a las últimas y gloriosas victorias del Cordero, y ban conquistado el merecido nombre de escogidos y leales". (Ibid., pp. 326-327.)
} 
tercera persona, Jane, erradica la presencia inminente de la otra Jane que, como nos dice Virginia Woolf, es capaz de atrapar al lector porque nunca se ausenta, porque lo obliga a ver las cosas como ella las ve, porque nunca lo trata de engañar $y$, sobre todo, porque registra sentimientos y no ideas o pensamientos. ${ }^{13}$ Entonces, ino es verdaderamente significativo el hecho de que la novela cierre con la cita textual de una carta de St. John Rivers? ¿Y que esta cita no se refiera a ningún aspecto práctico de la vida cotidiana, sino a la entrega espiritual de la existencia de un mártir, al que Jane no quiso acompañar, y del que, además, no conocemos mucho?

Independientemente del hecho de que para algunos críticos esta conclusión constituye una especie de desdoblamiento de la labor educativa/evangelizadora de Jane -St. John realiza entre los "paganos" lo que Jane se queda a hacer entre los suyos, ya dentro de la sacra institución del matrimonio - creo que, en efecto, no logra sino mostrar la aceptación, quizá inconsciente, de la retórica y los principios de la sociedad victoriana y del imperialismo por parte de Jane y, en este caso, por ende, de su autora, Charlotte Brontë.

Ahora bien, si una noción de Englishness o 'anglicidad' define en gran medida la fortaleza espiritual de Jane Eyre, este concepto ideológico es aun más penetrante en las figuras de Edward Rochester y St. John Rivers, quienes tienen una idea clara y definida de la inferioridad (y negatividad) del "Otro": el Caribe, e incluso Francia, para Rochester, y la India, para St. John Rivers. El grado de empuje de estos dos personajes desempeña un papel fundamental en el desarrollo de la protagonista, pero también nos deja ver los resquicios ideológicos que, en última instancia, hacen que Jane Eyre sea una novela un tanto contradictoria.

A pesar del ditirambo fervoroso del final, la actitud de Jane hacia St. John Rivers es bastante ambivalente. Jane rechaza casi visceralmente el concepto que éste tiene de la religión como sumisión total de los instintos y el espíritu al servicio de Dios ( $\mathrm{y}$ de él mismo como su representante?), de igual manera que había rechazado y despreciado al hipócrita Sr. Brocklehurst en su niñez. A nivel personal, no acepta el llamado de su primo para que lo acompañe a la India, entre otras cosas, porque siente que éste limitaría severamente su naturaleza humana. St. John Rivers representa, para Jane, la falta de amor y caridad en la religión y muestra una arrogancia espiritual tan inflexible que le es intole-

\footnotetext{
${ }^{13}$ Véase Virginia WoOLF, "Charlotte Brontē"[1916], en The Essays of Virginia Woolf, vol. If, 1912-1918. Nueva York, Havest/Harcourt Brace Jovanovitch, 1987, pp. 26-32.
} 
rable. Por tanto, la aceptación y mitificación incondicional de la labor que su primo realiza en la India hace que la conclusión de la novela sea por demás ambigua.

En cuanto a la adoración que Jane siente por Rochester hay mucho que decir. Por el momento quiero dejar de lado algunas lecturas de la novela en las que Rochester aparece o bien como un héroe byroniano cuyo atractivo radica en su áspero encanto, en su vida misteriosa, en sus modales bruscos que ocultan emociones trágicas, o bien como el contrapunto pasional de la frialdad de St. John Rivers.

Quiero concentrarme, más bien, en su papel como eje central de la novela, pero siempre en relación con el secreto que lo persigue, pues a pesar de que algunos críticos, como Norman Sherry, consideren que la esposa demente es un elemento innecesario dentro de la trama, ${ }^{14}$ creo que ésta no sólo ayuda a definir el carácter y la personalidad de Jane Eyre sino que, de hecho, le agrega toda una dimensión ideológica a la novela.

No hay que olvidar que el lector siempre percibe a Rochester a través de Jane, quien bastante a menudo actúa como una narradora poco confiable. A pesar de que Jane evalúa con frecuencia el carácter de Rochester $y$, seamos justos, lo hace con bastante honestidad, éste no llega nunca a ser un personaje convincente (ni agradable) a los ojos del lector. Aun sin la ayuda de Wide Sargasso Sea (como veremos más adelante), una primera lectura de Jane Eyre deja un mal sabor de boca en cuanto a la apasionada sumisión de Jane ante este hombre que no deja de ser altanero, orgulloso, prejuicioso, manipulador e hipócrita. Ni siquiera esa acción aparentemente heroica de querer salvar a su esposa Bertha del fuego (ni la ceguera y la mutilación subsecuentes) logran hacerlo un personaje simpático.

¿Y por qué nos resulta este héroe, este protagonista, tan antipático, cuando casi por definición los héroes deben atraer nuestras simpatías? Pues precisamente por el tratamiento que le da a las mujeres que lo rodean quienes, dicho sea de paso, a excepción de Jane y de Blanche Ingram, son todas extranjeras. A pesar de su aparente fortaleza de espíritu, Rochester obtiene el amor de Jane a raiz de una actitud lastimera y autocompasiva. Jane descubre y analiza sus defectos, pero lo que la atrae finalmente es el hecho de que Rochester fue la víctima de una serie de agravios en su juventud. Y asi llegamos a un paralelismo que sólo sirve para acentuar las contradicciones de la novela: tanto Jane

\footnotetext{
14 Véase Norman SHERry, Charlotte and Emily Brontë. Londres, Evans Brothers Ltd., 1969 (Literature in Perspective), p. 69.
} 
como Rochester han experimentado un largo proceso de aprendizaje, pero mientras Jane se ha fortalecido espiritualmente, Rochester nunca logró enfrentar y superar las condiciones adversas.

Así, a pesar de su riqueza y su posición social, Rochester se ve a sí mismo como la víctima de su pasado. En el capítulo catorce, le dice a Jane:

"I started, or rather (for, like other defaulters, I like to lay half the blame on ill-fortune and adverse circumstances) was thrust on to a wrong track, at the age of one and twenty, and have never recovered the right course since; but I might have been very different; I might have been as good as you - wiser-almost as stainless. I envy you your peace of mind, your clean conscience, your unpolluted memory. Little girl, a memory without blot or contamination must be an exquisite treasure - an inexhaustible source of pure refreshment: is it not?"

"How was your memory when you were eighteen, sir?"

"All right then; limpid, salubrious: no gush of bilge water had turned it to fetid puddle. I was your equal at eighteen - quite your equal. Nature meant me to be, on the whole, a good man, Miss Eyre; one of the better kind, and you see I am not so [...] I am not a villain [...] but owing, I verily believe, rather to circumstances than to my natural bent, I am a trite, commonplace sinner, hackneyed in all the poor petty dissipations with which the rich and worthless try to put on life [...] When fate wronged me, I had not the wisdom to remain cool; I turned desperate; then I degenerated" (pp. 166-167; el subrayado es mio)..$^{15}$

15 “Comencé, o mejor dicho - como a muchos pecadores me agrada achacar la mitad de la culpa a la desgracia y a las circunstancias adversas - fui arrojado a un camino tortuoso a los veintiún años, y desde entonces no he recuperado la línea recta; pero pude haber sido muy diferente, pude haber sidotan bueno como usted, y casi tan puro. Le envidio la paz de espíritu, la conciencia limpia, la memoria impoluta. Niña, una memoria sin mácula ni contaminación debe ser un tesoro exquisito, una fuente inacabable de frescura en eșta árida existencia. ¿No es así?

"— ¿Cómo era su memoria a los dieciocho años, señor?

"-Entonces era espléndida: límpida, incontaminada; ningún chorro de agua la había convertido en fétido pantano. A los dieciocho años era como usted, exactamente como usted. La naturaleza me hizo, en conjunto, un hombre bueno, señorita Eyre, de los mejores, y ya ve que ahora no lo soy [...] Pero le doy mi palabra que no soy malvado [...] Pero creo en cambio ser, más como consecuencia de las circunstancias que a causa de mi carácter natural, un pecador vulgar, acostumbrado a todas las pequeñas disipaciones con que los ricos indignos tratan de llenar su vida [...] Cuando la suerte me castigó, no tuve la prudencia necesaria para mantenerme impasible; me desesperé hasta degenerar por último". (Ibid., pp. 99-100. Los subrayados son míos.) 
Ahora bien, no es difícil determinar dentro de la trama cuál fue la experiencia que contaminó un alma tan "limpia", "incontaminada" y "pura" como la del joven Rochester: su estancia en las islas del Caribe. Casi sin sentirlo, Jane Eyre ha caído en ese estereotipo cultural de la naturaleza degenerada del "Otro" para definir la identidad propia. A partir de este episodio ( y cabe notar que ni siquiera hemos llegado a la mitad de la trama) las acciones y actitudes de Rochester se justifican, a los ojos de Jane y de Rochester mismo, por esa experiencia misteriosa. A partir de aquí, también, se da un doble movimiento en la definición de los protagonistas, pues mientras que Jane cree a pie juntillas lo que le dice Rochester (aunque el lector no quede convencido del todo), Rochester sólo se engaña a sí mismo, y su personaje se torna así cada vez más detestable.

El viaje de Rochester al Caribe no es un acontecimiento extraordinario, como podría aparecer en la trama de Jane Eyre. De hecho, sugiere apenas una de las tantas formas en las que la expansión colonialista del imperio británico modificó radicalmente la naturaleza de la sociedad inglesa. Como dice Raymond Williams, la emigración a las colonias se veía como una solución para la pobreza, para la disidencia religiosa y para la sobrepoblación urbana. Entre las clases acomodadas, la emigración se convirtió en otra opción más para los hijos menores de las familias terratenientes, quienes no heredaban las riquezas del padre. En la literatura del periodo este elemento es recurrente; pensemos sólo en el misterioso viaje de Heathcliff en Wuthering Heights, o en las innumerables novelas de aventuras de Haggard o Henty, en las que el protagonista adquiere una gran fortuna después de pasar un lapso en las colonias y retorna a Inglaterra para situarse un peldaño más arriba en la escala social. ${ }^{16}$

Para Rochester, la alternativa que le escoge su padre no es entonces un acto de maldad como él lo sugiere, sino sólo una de las tantas opciones disponibles en esa época. Existe, quizás, una diferencia: Rochester no hará el viaje en busca de un refugio idílico, ni para escapar de la persecución religiosa ni buscando honestamente una oportunidad de hacer fortuna. El motivo del viaje es adquirir una esposa, como se adquiere una propiedad. Obviamente, los lectores de fines del siglo xx no le podemos exigir a Rochester que muestre una actitud crítica frente a una situación establecida y aceptada a mediados del siglo XIX; pero aun así,

${ }^{16}$ Véase Raymond WILliams, The Country and the City. Londres, The Hogarth Press, 1985, pp. 280-281. 
y dentro de la estructura interna de la novela, su énfasis en la degeneración espiritual que el viaje le produjo continúa siendo poco convincente.

Para la mayoria de los críticos de Jane Eyre la locura de Bertha Rochester tiene funciones simbólicas. Para algunos, curiosamente, la locura de Bertha simboliza el extremo amenazante de la pasión física desbocada (representada por Rochester mismo), un extremo que puede llegar a la degeneración completa de cuerpo y espíritu. Para otros, como Gubar y Gilbert, Bertha constituye el avatar psicológico de Jane, el doble que esconde las ansiedades y miedos ocultos de la mujer victoriana. ${ }^{17}$ Sin embargo, estas lecturas consideran la demencia de Bertha como algo intrínseco a su persona y, como dicha locura nos llega a través de la mediación Rochester-Jane, se da por sentado que es una consecuencia intrínseca de que Bertha sea jamaiquina.

Llegamos entonces a una de las formas más socorridas de clasificar y homogeneizar al "Otro", al bárbaro. Jane Eyre (y algunos de los lectores a los que se dirige) acepta sin cuestionarse la demencia de Bertha y, aunque reconoce su humanidad ("Sir... she cannot help being mad", p. $328),{ }^{18}$ tolera el trato que ésta recibe de Rochester.

Uno de los grandes silencios de Jane Eyre es precisamente que la transacción hecha por Rochester para casarse con Bertha coincide con el periodo de colonización de las islas del Caribe por parte de Inglaterra. Aun más, sin proponérselo, en la figura de Bertha Rochester, Charlotte Brontë sintetizó simbólicamente, y con gran ironía, una serie de paradojas inherentes a todo proceso de colonización. Como afirma el crítico brasileño Alfredo Bosi, en su magistral Dialéctica da colonização, la colonización es un proyecto totalizante cuyas fuerzas motrices siempre encontrarán sus raíces en la etimologia misma de la palabra. Cultura, culto y colonización se derivan del mismo verbo latino colo: vivo, ocupo la tierra y la trabajo. Y en su acepción más amplia, el proceso conlleva también la realidad histórica de ocupar un nuevo suelo, explotar sus bienes y recursos, y someter a los naturales del lugar, no sólo en lo físico

17 Véase, por ejemplo, M. H. SCARGILL, "Poetic Symbolism in Jane Eyre", en Miriam ALLOTT, comp., Charlotte Brontē, Jane Eyre and Villette, A Selection of Critical Essays. Londres, Macmillan, 1973 (The Casebook Series), p. 179. También Sandra M. GILBERT y Susan GuBAR, The Madwoman in The Attic. The Woman Writer and the NineteenthCentury Literary Imagination. New Haven/Londres, Universidad de Yale, 1984, cap. 10.

18 “Señor... ella no tiene la culpa de estar demente". (Ch. BRONTÉ, Jane Eyre, ed. cit., p. 218.) 
y lo económico, sino también moral, cultural y espiritualmente. ${ }^{19}$ Sin tener conciencia de ello, Brontë lleva este fenómeno incluso un paso adelante. Después de usar, explotar y someter a Bertha, Rochester la rechaza como algo maligno y corrupto, con lo que preferiría nunca haber estado en contacto.

En un magnífico ejemplo de hipertextualidad, Wide Sargasso Sea, la novela de Jean Rhys, da voz a Bertha Rochester y a Rochester mismo, y al hacerlo le da una nueva dimensión al texto de Brontë, no sólo en el nivel narrativo, sino también en el ideológico, cultural e incluso crítico. Después de leer Wide Sargasso Sea se pierde toda la inocencia de una lectura de Jane Eyre inscrita dentro de criterios ingleses/occidentales. Wide Sargasso Sea justifica los motivos del lector insatisfecho con el desarrollo y conclusión de Jane Eyre, llena los silencios narrativos de ésta, materializa sus abstracciones y clarifica sus ambigüedades. Pero más que eso, se constituye en un temprano representante de esa nueva tradición literaria que aún no tiene un nombre bien definido, pero que aquí llamaré literatura poscolonial.

Wide Sargasso Sea posee, entonces, una dimensión histórica y cultural que no debemos ignorar, pues desmitifica algunas de las nociones preconcebidas que los europeos tienen sobre los paises colonizados. En efecto, cumple con una de las funciones centrales de este tipo de literatura, la de dejarnos ver el transcurso de la historia, lo que hay detrás -a nivel humano, individual y social- de esos extensos fenómenos históricos y culturales de apropiación que sólo quedan sugeridos en una gran parte de la literatura inglesa.

Raymond Williams argumenta que el proceso colonizador está enraizado dentro del inconsciente inglés que permanece, de hecho, sin un registro claro y directo de la experiencia colonial (sin dejar de lado, por supuesto, la obra de escritores como E. M. Foster, George Orwell o Joyce Cary). Por lo tanto, apenas es saludable que estas nuevas literaturas recreen, desde su perspectiva propia, aquellas experiencias amargas - vividas por los pueblos colonizados- que dieron lugar a la acumulación de grandes fortunas que a su vez se convirtieron, en la Gran Bretaña, en las mansiones solariegas y el modo de vida que éstas implican. Así, estas obras -entre las que se incluye Wide Sargasso Sea-revierten la imagen cultural de los pueblos colonizados; presentan, en términos reales, lo que oficialmente se había ofrecido a los lectores ingleses como

19 Véase Alfredo Bosı, Dialéctica da colonização. San Paulo, Companhia das Letras, 1992, pp. 13-15. 
simple barbarie o salvajismo. Es decir, dejan ver las tensiones internas de sociedades rurales que fueron invadidas y transformadas por un sistema ajeno, a menudo brutal. ${ }^{20}$

Al humanizar la figura de Bertha Rochester, Jean Rhys rompe de un solo golpe con la estructura ideológica de Jane Eyre, pues relativiza y debilita aquellos elementos que conforman la fortaleza espiritual de la protagonista inglesa y que he definido como la 'anglicidad' o esencia de 10 inglés. La demencia de muchas mujeres victorianas es, sobra decirlo, una manifestación de la represión y el abuso sexual y psicológico de que eran objeto. Pero la demencia de Bertha Rochester -además de incluir este fenómeno- conlleva también la cosificación de su persona que, cabe decirlo, se había iniciado aun antes de la llegada de Rochester a Jamaica. Así, su locura no es innata y hereditaria, como lo reitera hasta el cansancio Rochester; es, en cambio, el producto de un proceso histórico que, llevado a sus últimas consecuencias, hace que los individuos pierdan su identidad.

Así, al contrario de la voz asertiva y la estructura lineal y directa que caracteriza a Jane Eyre, en Wide Sargasso Sea existen dos voces narrativas que componen la estructura de la trama. La primera y la tercera partes están narradas por Antoinette Cosway, mientras Rochester narra la segunda. La contraposición de puntos de vista le da una textura narrativa muy interesante a la novela, pues no sólo percibimos las perspectivas diferentes de las acciones de los dos protagonistas, sino también varias oposiciones culturales e ideológicas acerca de los conceptos de nación, raza, género, sexo y locura, entre otros.

En la primera parte, la narración en primera persona de Antoinette está llena de dudas y ambigüedades. Es, por así decirlo, una narración impresionista, compuesta de episodios sumamente visuales que, sin grandes explicaciones, recrean la atmósfera asfixiante y opresiva de la Jamaica de principios del siglo XIX. Al igual que la narradora Jane Eyre, Antoinette Cosway transmite los recuerdos e impresiones de su infancia, pero a diferencia de la primera, Antoinette muestra una conciencia extraordinaria de los cambios sociales que ocurren a su alrededor. Jane Eyre se sabe diferente del resto de su familia adoptiva, los Reed. Pero incluso aunque sabe que éstos la rechazan por ser huérfana y porque su madre, al casarse, había descendido en la escala social, está muy consciente de las jerarquías y de un sentido de unidad social. Antoinette, 
por su lado, manifiesta una falta de identidad social y personal desde los primeros párrafos de la novela:

They say when trouble comes close ranks, and so the white people did. But we were not in their ranks. The Jamaican ladies had never approved of my mother, "because she pretty like pretty self" Christophine said.

She was my father's second wife, far too young for him they thought, and, worse still, a Martinique girl. When I asked her why so few people came to see us, she told me that the road from Spanish Town to Coulibri Estate where we lived was very bad and that road repairing was now a thing of the past. (My father, visitors, horses, feeling safe in bed - all belonged to the past. $)^{21}$

Los dos primeros párrafos ejemplifican lo que serán varios patrones recurrentes a lo largo de la novela. El más notable, quizá, es la presencia de un elemento impersonal, ajeno -representado por el pronombre "they", "ellos", así como por las referencias a algo tangible, sólo sugerido, y que es el contexto histórico que la protagonista no puede aprehender-, que resalta el aislamiento de Antoinette. Surge entonces su primera característica: a pesar de que su padre era inglés, los blancos no las aceptan ni a ella ni a su madre, pues ésta proviene de Martinica y no se sabe si lleva sangre negra.

Por otro lado, como se verá sólo unos párrafos más adelante, el caballo de su madre - uno de los últimos contactos con ese mundo de "antes"- muere envenenado misteriosamente por los negros del lugar. Luego entonces, Antoinette y su madre, ya viuda, no pertenecen ni al mundo de los blancos ni al de los negros, un hecho que queda reflejado en las agresiones verbales de las que son victimas: para los negros son

21 Jean RHYS, Wide Sargasso Sea [1966]. Londres, Penguin, 1968, p. 15. De aquí en adelante todas las referencias a la novela corresponderán a esta edición, e indicaré la página entre paréntesis. "Dicen que, en los momentos de peligro, hay que unirse y, por eso los blancos se unieron. Pero nosotros no formamos parte del grupo. Las señoras de Jamaica nunca aceptaron a mi madre, debido a que era 'muy suya, muy suya', como decía Christophine.

"Era la segunda esposa de mi padre, muy joven para él, según decían las señoras de Jamaica, y, peor todavía, procedía de Martinica. Cuando le pregunté por qué tan poca gente nos visitaba, me dijo que la carretera que iba desde Spanish Town a Coulibri Estate, donde vivíamos, era muy mala y que, ahora, la reparación de las carreteras había pasado a la historia. (También habían pasado a la historia mi padre, las visitas, los caballos y el sentirse segura en cama.)" (Las referencias a esta versión en español corresponden a Ancho mar de los Sargazos. Trad. de Andrés Bosch. Bruguera, Barcelona, 1982, p. 15.) 
"the white cockroaches" (las cucarachas blancas); para los blancos, "the white niggers" (las negras blancas).

Por si fuera poco, en esos párrafos iniciales queda delineado el concepto histórico del periodo: poco después de la Emancipación de los esclavos, los colonos ingleses esperan ser compensados por el gobierno inglés y mientras tanto ven cómo las propiedades decaen y las personas pierden toda esperanza; los negros, liberados ya, son víctimas del desempleo, la pobreza, la inactividad y el resentimiento; la nueva clase dominante sigue como si nada hubiera pasado, indiferentes a las calamidades y discriminando a los hacendados venidos a menos.

$Y$ en medio de todo esto, Antoinette vive su infancia prácticamente sola, olvidada por su madre - agobiada ésta por el retraso mental de su hijo pequeño y por las premuras económicas, pero consciente de su belleza pasajera - y al cuidado de su sirvienta negra, Christophine, quien, como esclava, había sido un obsequio de bodas a su madre, aunque después de la Emancipación había decidido quedarse.

Antoinette tiene una doble función simbólica que resulta de la situación imperialista. Por un lado, muestra la pérdida de identidad y degeneración moral de todo aquel involucrado en dicho fenómeno, incluso el colonizador. Por otro lado, como mujer y como criolla, llega a representar a los oprimidos, pues, como dice Rochester, ya no es posible aceptarla como ser humano "completo" (digase europeo): "Long, sad, dark alien eyes. Creole of pure English descent she may be, but they are not English or European either" (p. 56). ${ }^{22}$

$Y$ ciertamente Antoinette, al igual que su madre, posee una característica muy poco inglesa: la sensualidad, resultado, parece ser, de que "she have the sun in her", como dice Christophine (p. 130). ${ }^{23}$ Esta sensualidad es su mayor atractivo, pero también la causa de destrucción, pues desata en Rochester una serie de sentimientos e instintos contradictorios que no puede controlar. En Jane Eyre, Rochester describe su larga búsqueda de la mujer "perfecta" tanto en el Caribe como en Europa. No obstante estar convencido de su rectitud moral, su comportamiento deja mucho que desear. Además de Antoinette, sostiene relaciones con varias mujeres europeas quienes, por el solo hecho de aceptar ser sus amantes, pierden ante sus ojos toda calidad moral. La francesa Céline

22 "[Oscuros ojos alargados y tristes, extraños.] Quizá sea criolla de puro linaje inglés, pero sus ojos no son ingleses, ni tampoco europeos". (Jbid., p. 67. La frase entre corchetes está omitida en la traducción de Bruguera.)

23 “" [...] lleva el sol en el cuerpo" (Ibid., p. 163). 
Varens, la italiana Giacinta y la alemana Clara son bellas, pero carecen, según él, de valores y sólo logran que un hombre se desprecie a sí mismo:

Hiring a mistress is the next worse thing to buying a slave: both are often by nature, and always by position, inferior: and to live familiarly with inferiors is degrading. I now hate the recollection of the time I passed with Céline, Giacinta, and Clara (p. 339) ${ }^{24}$

El detonador de este proceso degenerativo, lo sabemos ya, fue Antoinette misma, quien corrompió la inocencia (p. 166) de este joven (aunque, como él mismo dice en otro punto era un "wild boy indulged from childhood upwards" [p. 247]). ${ }^{25}$ Pero analicemos su versión:

When I left college, I was sent out to Jamaica, to espouse a bride already courted for me. My father said nothing about her money; but he told me Miss Mason was the boast of Spanish Town for her beauty: and this was no lie. I found her a fine woman, in the style of Blanche Ingram: tall, dark, and majestic. Her family wished to secure me, because I was of a good race; and so did she. They showed her to me in parties splendidly dressed. I seldom saw her alone, and had very little private conversation with her. She flattered me, and lavishly displayed for my pleasure her charms and accomplishments. All the men in her circle seemed to admire her and envy me. I was dazzled, stimulated: my senses were excited; and being ignorant, raw, and inexperienced, I thought I loved her (p. 332; el subrayado es mio). ${ }^{26}$

24 "Contratar una meretriz es apenas menos malo que comprar un esclavo. Ambos son inferiores, a menudo por la naturaleza y siempre por su posición; y vivir familiarmente con nuestros inferiores resulta degradante. Ahora odio el recuerdo de la época que pasé con Celina, Jacinta y Clara". (Ch. BRONTE, Jane Eyre, ed. cit., pp. 225-226.)

25 "[...] un niño salvaje, mimado desde la infancia". (Traducción mia, pues la versión de Porrúa no corresponde. En todo caso, la p. es la 158.)

26 "Cuando abandoné el colegio, se me envió a Jamaica para casarme con una prometida que ya había sido cortejada para mí. Mi padre no me dijo nada de su dinero; díjome, en cambio, que la señorita Mason era el orgullo de Puerto España por su belleza. Y no era mentira, pues encontré en ella una espléndida mujer, por el estilo de Blanca Ingram: alta, morena y majestuosa. Su familia queria asegurarme por mi noble abolengo, y también la señorita Mason tenía la misma aspiración. Me la presentaban en fiectas, espléndidamente vestida. Rara vez pude verla sola, y tuve muy pocas conversaciones privadas con ella. Por su parte, la señorita Mason me lisonjeaba, y desplegaba generosamente en mi honor sus encantos y sus dones. Todos los hombres de su círculo parecían admirarla y envidiarme. Yo estaba deslumbrado, estimulado, y mis nervios se excitaban. Y como era ignorante, sencillo e inexperto, pensé que la amaba". (Ibid., pp. 220-221. Los subrayados son míos.) Una vez más, la traducción pierde las connotaciones del texto original en términos clave. Aqui, "abolengo" pierde la fuerza de "race" ("raza") del original. 
Vemos aquí la fractura inicial de una relación fundamentada en la desigualdad. El viaje de Rochester al Caribe ni siquiera tiene el próposito de "colonizar", es decir, llevar la "civilización", sino sólo de actuar como un mercenario. Por 10 tanto, Rochester sólo puede percibir el territorio de la conquista imperialista, en palabras de la crítica G. Ch. Spivak, como un "infierno". ${ }^{27}$

Para Rochester, Antoinette es intrínsecamente inferior y él un semental víctima del hechizo de este ser medio humano, medio animal. En Jamaica, y posteriormente en una de las islas Barlovento, Rochester nunca se identifica con el medio ambiente y, al igual que le sucede con Antoinette, lo percibe de forma ambivalente. A la vez que lo impresiona la belleza del paisaje, su exuberancia, sus silencios, sus olores, to apabullan. Al no poder descifrar sus misterios y, también, llegar a conocerse a sí mismo, no le queda más que odiarlo:

I hated the mountains and the hills, the rivers and the rain. I hated the sunsets of whatever colour, I hated its beauty and its magic and the secret I would never know. I hated its difference and the cruelty which was part of its indifference and the cruelty which was part of its loveliness. Above all I hated her. For she belonged to the magic and the loveliness. She had let me thirsty and all my life would be thirst and longing for what I had lost before I found it (p. 141; el subrayado es mio). ${ }^{28}$

La sensualidad del paisaje, compartida por Antoinette, rompe el equilibrio interno de Rochester, representado en la muy inglesa (de acuerdo con E. M. Forster) capacidad de ocultar sus sentimientos. A diferencia de la vulnerabilidad de los lugareños, que radica en su expresividad, Rochester se siente fuerte por su frialdad, "How old was I when I learned to hide what I felt? A very small boy. Six, five, ven earlier. It was necessary, I was told, and that view I have always

27 Véase Gayatri Chakravorty SPIVAK, “Three Women's Texts and a Critique of Imperialism", en Catherine BELSEY y Jane MOORE, comps., The Feminist Reader. Essays in Gender and the Politics of Literary Criticism. Londres, Macmillan, 1990, p. 180.

28 “Odiaba las montañas y las colinas, los ríos y la lluvia. Odiaba los ocasos, fuera cual fuese su color, odiaba su belleza y su magia, y odiaba el secreto que nunca llegaría a descubrir. Odiaba la indiferencia de aquel lugar, así como la crueldad que formaba parte de su belleza. Y, sobre todo, odiaba a Antoinette. Sí, porque pertenecía a aquella magia y a aquella belleza. Me había dejado sediento, y toda mi vida sentiría sed y deseo de aquello que habia perdido antes de poder encontrarlo". (J. RHYS, Ancho mar..., p. 177.) 
accepted" (p. 85). ${ }^{29}$ Sin embargo, al mismo tiempo, siente una pasión desbocada por su nueva esposa:

As for the happiness I gave her, that was worse than nothing. I did not love her. I was thirsty for her, but that is not love. I felt very little tenderness for her, she was a stranger to me, a stranger who did not think or feel as I did.

One afternoon the sight of a dress which she'd left lying on her bedroom floor made me breathless and savage with desire. When I was exhausted I turned away from her and slept, still without a word or caress (p. 78). ${ }^{30}$

La posesión sexual de Rochester es sólo una de las varias formas de apropiación que ejerce sobre Antoinette, pero es la que simboliza, por su violencia, el grado de destrucción que ejerce sobre ella. El proceso gradual de contaminación y degeneración del que Rochester es víctima, en su versión a Jane Eyre, se presenta en Wide Sargasso Sea en su dimensión real. El padrastro de Antoinette, el señor Mason, le ofrece una dote de 30000 libras, mismas que le paga en cuanto se casan, sin preguntas ni condiciones (p. 59). ${ }^{31}$ Las propiedades de Antoinette pasan a su posesión. A pesar de que en un momento dado, Antoinette no acepta casarse con él y su tía Cora lucha por evitar el matrimonio, su padrastro y su hermanastro (el mismo Richard que acudirá a Inglaterra a denunciar a Rochester) la obligan; se convierte así en propiedad de Rochester, quien no sólo ejerce violencia física sobre ella - como lo hace notar Christophine al descubrirle moretones - sino también violencia psicológica y espiritual.

Rochester manipula la falta de identidad social de Antoinette ("I often wonder who I am and where is my country and where do I belong

29 “ ¿Qué edad tenía yo, cuando aprendí a ocultar mis sentimientos? Era un niño de muy pocos años. Seis, cinco, quizá menos. Me dijeron que era necesario, y siempre lo he creído así". (Ibid., p. 106.)

30 "En cuanto a la felicidad que [yo] le daba, era peor que nada. No la amaba. Estaba sediento de ella, pero esto no es amor. Sentía hacia ella muy poca ternura, era una desconocida para mí, una desconocida que no pensaba ni sentía como yo.

"Una tarde, la visión de un vestido de mi mujer, caído en el suelo de su dormitorio, suscitó en mi un deseo salvaje que me dejó jadeante. Cuando quedé agotado, me aparté de ella y me dormí, sin decirle una palabra, sin hacerle una caricia". (Ibid., p. 95.)

31 Ibid., p. 70. 
and why was I ever born at all" [p. 85]),,$^{32}$ pasando del dominio sexual por la sumisión psicológica:

"Why did you make me want to live? Why did you do that to me?" [le pregunta Antoinette].

"Because I wished it. Isn't that enough?"

"Yes, it is enough. But if one day you didn't wish it. What should I do then? Suppose you took this happiness away when I wasn't looking..."

"And lose my own? Who'd be so foolish?"

"I am not used to happiness", she said. "It makes me afraid".

"Never be afraid. Or if you are tell no one".

"I understand. But trying does not help me".

"What would?" She did not answer that, then one night whispered, "If I could die. Now, when I am happy. Would you do that? You wouldn't have to kill me. Say die and I will die. You don't believe me? Then try, try, say die and watch me die".

"Die then! Die!" I watched her die many times. In my way, not in hers. In sunlight, in shadown, by moonlight, by candlelight. In the long afternoons when the house was empty. Only the sun was there to keep us company. We shut him out. And why not? Very soon she was as eager for what's called loving as I was -more lost and drowned afterwards (p. 77; el subrayado es mío). ${ }^{33}$

hasta llegar a la negación total de su identidad cuando, de súbito, decide cambiarle el nombre a Bertha (no sin antes engañarla con la sirvienta mestiza Amélie, en el cuarto adjunto al de Antoinette y sabiendo que ella los escucha).

32 “[...] a menudo me pregunto quién soy, cuál es mi tierra, a qué mundo pertenezco, y por qué naci". (Ibid., p. 105.)

33 "- ¿Por qué me has hecho desear la vida? ¿Por qué me has hecho esto?

"-Porque quería que así fuera. ¿No te parece bastante?

"-Si, es bastante. Pero si llegara el día en que no lo quisieras, ¿qué haría? Supón que un día te llevaras nuestra felicidad, mientras yo estuviese distraída...

"- ¿Perdiendo la mía? ¿Crees que soy tan insensato?

"-No estoy acostumbrada a la felicidad. Me da miedo.

"-No tengas miedo jamás. Y si lo tienes, no se lo digas a nadie.

"-Comprendo. Puedo intentarlo, pero esto nada soluciona.

"- ¿Y cuál es la solución?

"No contestó a esta pregunta, pero una noche murmuró:

"-Me gustaría morime, ahora que soy feliz. ¿Quieres que lo hagamos? No tendrias que matarme, bastaría con que dijeras 'muérete', y me moriria. ¿No me crees? Anda, pruébalo, di 'muérete' y verás cómo me muero. 
Así, cuando llega el momento crítico de su estancia en el Caribe, que Rochester le describe con gran melodrama a Jane Eyre, la transvocalización de Rochester en Wide Sargasso Sea adquiere una dimensión apabullante, pues el lector percibe el grado de insensibilidad, crueldad e hipocresía de este personaje.

La supuesta locura congénita de Bertha, y su transformación en una criatura repulsiva, que para el Rochester de Jane Eyre son la causa de su corrupción espiritual y su infelicidad, para la Antoinette de Wide Sargasso Sea son en realidad el producto de un largo proceso de anulación de identidad. Los gritos e insultos vehementes que Rochester escucha en una calurosa noche caribeña - y a los que no atribuye una causa ciertatienen su origen, de hecho, en una pelea en la que él trata violentamente a Antoinette, le niega toda posibilidad de contacto físico, afectivo y espiritual, y culmina así con su proceso de "cosificación": "I could see Antoinette stretched on the bed quite still. Like a doll. Even when she threatened me with the bottle she had a marionette quality" (p. 123; el subrayado es mío). ${ }^{34}$

A partir de este punto se inician dos procesos paralelos, aunque opuestos, en la vida de Rochester y Antoinette/Marionette/Bertha: la salvación de Rochester del infierno caribeño y la condena permanente de Antoinette a la locura. En Jane Eyre, Rochester le platica a la institutriz que después de ese episodio "aterrador" (en el que él pensó incluso en el suicidio):

A wind fresh from Europe blew over the ocean and rushed through the open casement: the storm broke, streamed, thundered, balzed, and the air grew pure. I then framed and fixed a resolution [...] it was true Wisdom that consoled me in that honour, and showed me the right path to follow $[\ldots]$

The sweet wind from Europe was still whispering in the refreshed leaves, and the Atlantic was thundering in glorious liberty; my heart,

"-_Pues muérete! ¡Muérete!

"La vi morir muchas veces. Pero a mi manera, no a la suya. A la luz del sol, en la penumbra, a la luz de la luna, a la luz de las velas. En las largas tardes, cuando la casa estaba vacía. Sólo el sol nos hacía compañia, entonces. No lo dejábamos entrar. ¿Por qué? Muy pronto llegaba el momento en que Antoinette ansiaba tanto como yo el acto que se denomina amar, y, luego, quedaba más perdida y confusa que yo". (Ibid., pp. 94-95. Los subrayados son míos.)

34 "Vi a Antoinette tendida en cama, absolutamente inmóvil. Como una muñeca. Incluso cuando me amenazó con la botella, había en ella cierta calidad de marioneta". (Ibid., p. 154.) 
dried up and scorched for a long time, swelled to the tone, and filled with living blood - my being longed for renewal - my soul thirsted for a pure draught. I saw hope revive - and felt regeneration possible.

[...]

"Go", said Hope, "and live again in Europe: there it is not known what a sullied name you bear, nor what a filthy burden is bound to you. You may take the maniac with you to England; confine her with due attendance and precautions at Thornfield [...] That woman who has so abused your long-suffering, so sullied your name, so outraged your honour, so blighted your youth, is not your wife, nor are you her husband..." (pp. 335-336; el subrayado es mío). ${ }^{35}$

La versión de Rochester tiene su contrapunto en Wide Sargasso Sea, en donde existe una clara transmotivación y desvalorización de Rochester, y se rompe así no sólo con la autocomplacencia de éste sino también con la base ideológica que lo respalda:

[...] she [Antoinette] loves no one, anyone. I could not touch her. Excepting as the hurricaine will touch that tree - and break it. You say I did? No. That was love's fierce play. Now I'll do it.

She'll not laugh in the sun again. She'll not dress up and smile at herself in that damnable looking-glass. So pleased, so satisfied.

Vain, silly creature. Made for loving? Yes, but she'll have no lover, for I don't want her and she'll see no other.

The tree shivers. Shivers and gathers all its strenght. And waits [...]

She said she loved this place. This is the last she'll see of it. I'll watch for one tear, one human tear. Not that blank hating moonstruck face [...] If she [...] weeps, I'll take her in my arms, my lunatic. She's

35 “ Un viento fresco del Este [Europa en el texto original] sopló a través del océano,y se introdujo en mi habitación abierta. Estalló la tormenta, con viento y truenos, y el aire se hizo más puro. En ese momento adopté una decisión [...] porque [la verdadera sabiduría] fue a consolarme en aquella hora y me mostró el sendero que había de seguir.

"Todavía silbaba entre las hojas mojadas el dulce viento de Europa, y el Atlántico nugía en gloriosa libertad. Mi corazón, reseco y marchito desde hacía mucho tiempo, se dilató y llenó de sangre vivificadora, mi ser sintió ansia de renovación y mi alma sed de pureza. Vi renacer la esperanza, y sentí que la regeneración era posible [...]

"Ve -decía la Esperanza-a vivir de nuevo a Europa; allí desconocen que tu nombre está mancillado, y la carga que debes soportar. Puedes llevar contigo a Inglaterra a la loca y confinarla con las debidas precauciones y atenciones en Thomfield [...] Esa mujer, que en semejante forma ha abu sado de tu sufrimiento, que ha mancillado tu nombre, ultrajado tu honor y agolado tu juventud, no es tu esposa, ni tí su marido". (Ch. BRONTE, Jane Eyre, ed. cit., p. 223.) 
mad but mine, mine. What will I care for gods or devils or for Fate itself. If she smiles or weeps or both. For me.

Antoinette - I can be gentle too. Hide your face. Hide yourself in my arms. You'll soon see how gentle. My lunatic. My mad girl.

Here's a cloudy day to help you. No brazen sun.

No sun... No sun... (p. 136; subrayado en el texto). ${ }^{36}$

La inspiración divina expresada en las abstracciones "wisdom" y "hope", que provienen del aire puro de Europa y que representan toda una estructura política e ideológica, pierde toda su dimensión en la novela de Rhys, en donde se muestran, "en la práctica", los sucesos vividos que pierden su historicidad y se convierten simplemente en "ideales" 0 "valores" impuestos.

Rhys expropia y vacía de significado a los valores ideológicos personificados en la frágil figura de Rochester $\mathrm{y}$, al presentar a éste como un cretino, los convierte en símbolo de la rapiña europea. Se da entonces una paradoja bastante compleja, pues a pesar de que Rochester no pretende representar los valores imperialistas (a diferencia de St. John Rivers, Rochester carece de ideales, es, digamos, un ser apolítico y viaja al Caribe sólo como mercenario), sí se convierte, por su mera estancia en Jamaica, en representante de dichos valores. Mientras que Antoinette (como paradigma de una clase dominante ya desposeída) pierde su centro al carecer de una estructura social que la sostenga, Rochester, un mero intruso, adquiere poder gracias al sistema colonialista.

36 "'[... Antoniette] no quiere a nadie. Ni tocarla podría. Salvo del modo en que el huracán tocará aquel árbol, tronchándolo. ¿Dices que esto fue lo que hice? No. Aquello era furia de amar. Ahora, sí, lo haré.

"No volverá a reír al sol. No volverá a vestirse con esmero y a sonreírse a sí misma ante aquel maldito espejo. Tan contenta, tan satisfecha.

"Tonta y vana criatura. ¿Nacida para amar? Sí, pero no tendrá amante, porque yo no la deseo, y no verá a ningún otro.

"El árbol se estremece. Se estremece y reúne todas sus fuerzas. Espera.

"Dijo que amaba este lugar. No volverá a verlo. Esperaré a veruna lágrima, una lágrima humana. No esa cara vacia, animada por el odio, enloquecida por la luz de la luna. Escucharé [...] Y si dice adiós, quizá adieu... Adieu, adieu... Y si también ella lo dice, la tomaré en brazos, tomaré en brazos a mi loca. Está loca pero es mia, mía. ¡Qué me importan los dioses y los demonios, o el propio Destinol Si sonríe o llora, o ambas cosas a la vez. Para mi.

"Antoinette, también yo puedo prodigar dulzura. Esconde tu rostro. Escóndete, pero hazlo en mis brazos. Pronto verás cuánta dulzura puedo dar. Mi loca. Mi muchacha loca.

"Y he aquí que el día gris viene en mi ayuda.

"No hay sol ardiente. No hay sol... No hay sol..." (J. RHYS, Ancho mar..., pp. 170-171. Los subrayados están en el propio texto.) 
Creo que uno de los grandes logros de Rhys radica en que, además de darle voz a un personaje sometido, como Antoinette/Bertha, nos presenta de forma sutil mas convincente una recreación de la realidad de los países colonizados, una realidad que se convierte en mera imagen en la obra de muchos autores ingleses. Rochester, por el solo hecho de ser inglés, tiene la capacidad y autoridad implicita para silenciar a los que lo rodean, por la simple razón de que él los considera inferiores y por lo tanto, como a menudo le sucede a Lawrence, constituyen una amenaza. (La narración nos muestra varios ejemplos patentes del racismo "pragmático" de este personaje, que sólo se "atreve" a tocar a una mujer negra, Amélie, en el acto sexual, pero siente repugnancia por Christophine y los otros negros.)

El silencio es una de las fọmas de dominación que Rochester ejerce sobre Antoinette, al rehusarse a escuchar cualquier cosa que ella quiera decirle, desde una súplica hasta la historia de su vida, que él, por supuesto, ignora y considera sólo una mentira o el producto de su imaginación. De igual manera, Rochester intenta ignorar a Christophine, la nana negra, pero, en el aspecto político-intelectual, su relación es mucho más violenta.

Así como Antoinette queda envuelta en el silencio debido a su soledad, Christophine tiene la fortaleza de cuestionar los actos y actitudes de Rochester, pues ella es una mujer que sí pertenece al lugar. Es una mujer obeah, una sacerdotisa orgullosa de su independencia como mujer y de su recién adquirida libertad como ser humano, pero por eso mismo peligrosa para Rochester y el resto de los blancos de la isla, quienes la tienen clasificada como elemento potencialmente subversivo e incluso la han encarcelado. Christophine es la que "traduce", en el texto, muchos de los acontecimientos que para Antoinette son sólo rumores incomprensibles, es quien define bastante crudamente los efectos del imperialismo sobre la población nativa y quien tiene la capacidad, como establece Spivak, de juzgar que las prácticas rituales negras pertenecen a la cultura negra y no pueden ser usadas por los blancos como remedios baratos para los males sociales (como la falta de amor de Rochester por Antoinette). ${ }^{37}$ Cuando Christophine enfrenta directamente a Rochester y le echa en cara que simplemente ha usado a Antoinette para obtener su dinero, Rochester se siente amenazado y temeroso, listo para defenderse (p. 131). ${ }^{38}$ Sin embargo, Christophine sabe cuál es su lugar, y cuando Rochester la

37 Véase G. Ch. SPIVAK, op.cit., p. 185.

${ }^{38}$ J. RHYS, Ancho mar..., pp. 162-163. 
amenaza con traer a la policía ella simplemente se va y desaparece de la escena, después de responder a la sugerencia de que le puede escribir a Antoinette: "Read and write I don't know. Other things I know" (p. 133). ${ }^{39}$ Es decir, ella tiene los conocimientos de su cultura, pero se ha negado a adquirir los de la cultura invasora.

Christophine tiene una función equivalente a la de St. John Rivers en Jane Eyre, en el sentido de que encarna los valores ideológicos del lugar, pero mientras St. John tiene la última palabra en la narración de Jane Eyre (ya he establecido la razón), Christophine, como representante de la nación dominada, colonizada, simplemente tiene que desaparecer ante la amenaza de la Ley y el Orden. No hay que olvidar que Christophine se marcha dentro de la narración de Rochester, en la segunda parte de Wide Sargasso Sea, en donde, es obvio, no tiene ninguna posibilidad de participar activamente. Una vez fuerä Rochester tiene el camino abierto para hacer lo que quiera con Antoinette.

Es significativo que la única voz que Rochester decide escuchar es la de los rumores de la locura de Antoinette, rumores que inicia el medio hermano de ésta, Daniel Cosway, uno de los hijos ilegítimos que Cosway padre dejó regados por la isla. Daniel Cosway manipula los prejuicios sociales y raciales de Rochester y éste, aunque siente repugnancia porque Daniel es mulato y sin escrúpulos, termina por hacerle caso y repudiar a su mujer.

Wide Sargasso Sea concluye con la voz de Antoinette/Bertha, que narra su propia muerte. Antoinette ha perdido su corporeidad, pero al mismo tiempo mantiene una sensualidad que le permite estar en contacto (limitado) con el mundo exterior. Con la tercera parte de la novela, Rhys termina de revertir los valores implícitos en Jane Eyre, al convertir a Inglaterra -que había sido sólo una imagen intangible en la primera y segunda partes - en un mundo de cartón, gris, frio y sin vida. A diferencia de Jane, quien complementa su mitificación de Inglaterra con la lectura de libro que la ayuda a adquirir un sentido de identificación nacional mediante imágenes culturales de "nosotros" y los "otros", para Antoinette/Bertha Inglaterra simplemente no existe, pues el cuarto oscuro donde está encerrada no corresponde a la imagen de "chandeliers and dancing, $[\ldots]$ swans and roses and snow" (p. 92) ${ }^{40}$ que ella se había creado en el Caribe.

39 "Escribir y leer no sé. Otras cosas, si". (Ibid., p. 166.)

40 "[...] candelabros y bailes, cisnes, rosas y nieve". (Ibid., p. 115.) 
A pesar de su encierro, y aun cuando ha perdido conciencia de su cuerpo, Antoinette conserva su sensualidad. Al ver su imagen en el espejo cree que es el fantasma del que todos hablan (una vez más, como ha sucedido desde el inicio de la novela, existe una ruptura entre su visión de la realidad y lo que otros "dicen" de ésta), pero apenas se identifica a sí misma. Conoce bien su entorno, incluso las áreas de la casa que le tienen prohibidas, pero vive en un mundo de sueños que se entrelaza interminablemente con "la realidad". Así, el último episodio de la novela constituye la narración del sueño de su propia muerte que para ella no es sino la salvación, la fuga hacia su mundo propio y que significativamente, Rochester, en Jane Eyre, narra como una acción maléfica y suicida.

Para Spivak, el suicidio de Antoinette en Wide Sargasso Sea tiene la función de dejar el camino abierto para que Jane Eyre se convierta en la heroína feminista e individualista de la narrativa inglesa y esto, a su vez, compone una alegoría de la violencia epistémica del imperialismo, la construcción de un sujeto colonizado que se inmola a sí mismo para glorificar la misión social del colonizador. ${ }^{41}$ Pero considero que Rhys llega incluso un paso más adelante, pues si bien deja el camino abierto a la felicidad de la protagonista de la novela inglesa, también es cierto que tanto Jane Eyre como Rochester quedan como seres insensibles, autocomplacientes e hipócritas, cómplices no de un error, como Rochester quiere hacer cree a Jane (con la que si conversa y a quien si escucha) en el capítulo veinte, sino deí crimen que él intenta borrar. A pesar de su aparente desinterés político, Jane es, en cierta forma, cómplice también de los excesos del imperialismo al aceptar pasivamente, sin cuestionarse, la herencia de la riqueza que su tío acumuló en el Caribe.

La pureza y candidez de Jane Eyre, más que ser epítomes de fortaleza espiritual y de anglicidad, se convierten en símbolos del "inconsciente político" de la Inglaterra del siglo XIX, símbolos que justificaron, callar on y borraron la historia "real", vivida, del proceso imperialista y de su otra cara, el fenómeno de la esclavitud.

El gran mérito de Jean Rhys en Wide Sargasso Sea es que, además de dejar una obra de gran calidad literaria fue capaz de permitir al lector del siglo XX una reconstrucción de la novela del siglo XIX, una novela en la que la criatura-animal domesticada, la "Otra", se observa a sí misma y comprende la fractura de identidad (social, cultural, psicológica) de la que ha sido objeto. Jean Rhys rompe de tajo, entonces, con las nociones

${ }^{41}$ G. Ch. SpIVAK, op. cil., p. 185. 
del progreso y el nacionalismo estéticos que, como argumenta el crítico James Snead, fueron factores primordiales en la autorrepresentación narcisista de los europeos durante el siglo XIX, justamente en el momento en el que el colonialismo y el imperialismo realizaban su brutal incursión en las culturas del "Tercer Mundo". 42

Jean Rhys cumple, entonces, con los objetivos compartidos por las literaturas modernas de los países que fueron colonizados, y que se pueden resumir por el interés en reescribir su historia amordazada. Y de paso nos obliga a recordar, como dice Spivak, que a estas alturas ya no es posible leer la literatura inglesa del siglo XIX sin recordar que el imperialismo fue un elemento crucial de la representación cultural de Inglaterra para los ingleses y, creo yo, de la representación cultural del "Otro" por medio de la cual los ingleses lograron esa identificación propia.

${ }^{42}$ Véase James SNEAD, “European Pedigrees/African Contagions”, en Homi K. BHABHA, comp., Nation and Narration. Londres, Routledge, 1990, p. 235. 